\title{
Tax, price and cigarette brand preferences: a longitudinal study of adult smokers from the ITC Mexico Survey
}

\author{
Belén Sáenz de Miera Juárez, ${ }^{1}$ James F Thrasher, ${ }_{1}^{1,2}$ Luz Myriam Reynales Shigematsu, ${ }^{1}$ \\ Mauricio Hernández Ávila, ${ }^{1}$ Frank J Chaloupka ${ }^{3}$
}

\begin{abstract}
${ }^{1}$ Tobacco Control Research Department, Center for Population Health Research, National Institute of Public Health, Cuernavaca, Mexico ${ }^{2}$ Department of Health Promotion, Education and Behavior, Arnold School of Public Health, University of South Carolina, Columbia, USA ${ }^{3}$ Department of Economics and Health Policy Center, Institute for Health Research and Policy, University of Illinois at Chicago, Chicago, USA
\end{abstract}

\section{Correspondence to}

Belén Sáenz de Miera Juárez, Tobacco Control Research Department, Center for Population Health Research, National Institute of Public Health. Avenida Universidad 655, Colonia Santa María Ahuacatitlan, Cuernavaca, Morelos 62100, Mexico; belensaenzdem@yahoo.com.mx, bsaenzdemiera@insp.mx

Received 19 December 2012 Revised 15 August 2013 Accepted 5 September 2013 Published Online First 10 October 2013

\footnotetext{
To cite: Sáenz de Miera Juárez B, Thrasher JF, Reynales Shigematsu LM, et al. Tob Control 2014;23: i80-i85.
}

\section{ABSTRACT}

Background Recent tax increases in Mexico differed in structure and provided an opportunity to better understand tobacco industry pricing strategies, as well as smokers' responses to any resulting price changes.

Objectives To assess if taxes were passed onto consumers of different cigarette brands, the extent of brand switching and predictors of preference for cheaper national brands.

Methods Using data from three waves of the Mexican administration of the International Tobacco Control Survey, we analysed self-reported brand and price paid at last cigarette purchase. Generalised estimating equations were used to determine predictors of price and preference for national brands.

Results The average price of premium/international brands increased each year from 2008 to 2011; however, the price for discount/national brands increased only from 2010 to 2011. The percentage of smokers who smoked national brands remained stable between 2008 and 2010 but dropped in 2011. Factors related to smoking national brands as opposed to international brands included being male and having relatively older age, lower education, lower income and higher consumption.

Conclusions Tobacco industry pricing strategies in the wake of ad valorem taxes implemented in Mexico prior to 2011 had the impact of segmenting the market into discount national brands and premium international brands. The specific tax increase implemented in 2011 reduced the price gap between these two segments by raising the price of the national brands relative to the international brands. Evidence for trading up was found after the 2011 tax increase. These results provide further evidence for the relevance of tax policy as a tobacco control strategy; in particular, they illustrate the importance of how specific rather than ad valorem taxes can reduce the potential for downward brand switching in the face of decreasing cigarette affordability.

\section{BACKGROUND}

Increasing the price of cigarettes through taxation reduces prevalence, the level of consumption for those who continue smoking and smoking initiation. ${ }^{1-4}$ Previous research, however, also suggests that smokers may change their purchasing behaviour to minimise the effect of tax increases by switching to cheaper brands. For example, Tsai et $a l^{5}$ found that $17.4 \%$ of Taiwanese male smokers switched to lower-priced brands after a tax increase implemented in 2002. Also, based on information from 20 communities in the USA, Cummings et $a l^{6}$ found that the proportion of smokers who used discount brands increased from $6.2 \%$ in 1988 to $23.4 \%$ in 1993 as taxes and prices increased over this period. In contrast, a previous study for Mexico did not find evidence of this strategy as switching from international brands to cheaper national brands was as common as the opposite after the 2007 cigarette tax increase. ${ }^{7}$ Smokers may also switch to cigarettes higher in tar and nicotine as Evan and Farrelly found out using US data for 1979 and $1987 . .^{8}$

The effectiveness of tax increases can also be reduced by tobacco industry pricing strategies, such as absorbing part of these tax increases instead of passing them onto consumers. For example, one recent study shows that the tobacco industry has differently shifted taxes between price segments in the UK; while the price of high-priced brands has increased gradually, the price of low-priced brands has remained fixed between 2006 and 2009, which is associated with a large increase in the market share of the latter. ${ }^{9}$

Recent excise tax increases in Mexico have included taxes with and without a specific component. Each type of tax may produce a different tobacco industry pricing strategy, which in turn, can impact smokers' responses to this pricing; however, these topics have been understudied in low-income and middle-income countries. Specific taxes are monetary values per quantity (eg, pesos per cigarette), while ad valorem taxes are set as a percentage of the value of the products (eg, as a percentage of the price to the retailer or as a percentage of the price to the wholesaler). The main advantage of ad valorem taxes is that their real value is preserved as prices increase; the main disadvantages are that they require strong tax administration and are susceptible to undervaluation, which can exacerbate price differentials and brand switching. Specific taxes, on the other hand, entail low administrative requirements and are not subject to undervaluation but need to be periodically adjusted in order to keep their real value from being eroded by inflation. ${ }^{10}$

The cigarette excise tax (Special Production and Services Tax (SPST)) has been progressively increased in Mexico in recent years, from $110 \%$ of the price to the retailer in 2006 to $140 \%$ in 2007 , $150 \%$ in 2008 and $160 \%$ in 2009 . In addition, a specific component of MX\$0.04 (US\$0.003) per cigarette was added to the SPST in 2010, which was increased to MX\$0.35 (US\$0.03) in 2011. ${ }^{11}$ The STPS (both the ad valorem and specific 
component), together with the value-added tax (VAT) of $16 \%$ of the final price, accounted for $54.2 \%$ of the price to the public in $2006,58.9 \%$ in $2007,60.2 \%$ in $2008,61.4 \%$ in $2009,62.7 \%$ in 2010 and $68.8 \%$ in $2011 .^{12}$

Data from Mexico support evidence regarding the effectiveness of cigarette taxes in reducing consumption, ${ }^{7} 12$ 13 while suggesting that the two tobacco companies (PMI and BAT) that control $98 \%$ of the Mexican market have segmented the market into low-cost 'discount' cigarettes, mostly comprising national brands, and significantly higher-cost 'premium' brands, mostly comprising international brands. ${ }^{7}$ This process of market segmentation appears to have accompanied the ad valorem taxes that were implemented in the years prior to 2010. The specific tax should narrow the gaps between prices across brand types and thereby impede further segmentation of the market.

The objectives of this study were to assess if (1) cigarette tax increases were passed onto consumers and specially to test for differential effects for national-international brands, (2) the extent of brand switching and (3) predictors of preference for national brands.

\section{METHODS}

\section{Study sample}

Data were analysed from adult smokers who participated in the last three waves (wave 3 (2008), wave 4 (2010) and wave 5 (2011)) of the Mexican administration of the International Tobacco Control (ITC) Survey. The ITC Mexico Survey is a longitudinal survey designed to evaluate the effects of tobacco control policies promoted by the WHO Framework Convention on Tobacco Control (FCTC). ${ }^{14-16}$ Data collected in six cities at all the three waves were analysed in this study (Guadalajara, Mérida, Mexico City, Monterrey, Puebla and Tijuana). Stratified multistage sampling was used within the urban areas of each city, wherein census tracts and then block groups were selected with probability proportional to the number of households. Households were selected at random and visited up to four times to identify eligible adult smokers (18 years or older, who smoked at least once a week and had smoked at least 100 cigarettes in their lifetime). Up to one woman and one man were interviewed per household.

Sampling weights account for the probability of household selection and are adjusted for the number of smokers within the household; thus, weighted estimates are representative of the population in the urban areas sampled. Data from the last three waves of the ITC Mexico Survey were collected between November and December $2008(\mathrm{n}=1760)$, January and February $2010(n=1840)$ and March and April $2011(n=1845)$. Of the 1760 participants interviewed in 2008, 74\% $(n=1309)$ were successfully followed up in 2010; of the 1840 participants interviewed in 2010, 83\% were followed up in $2011(n=1519)$. To maintain sample size across waves, 531 new participants were recruited in 2010 and 326 in 2011 in order to replenish the sample. Replenishment involved the same protocol in randomly selected block groups within the originally selected census tracts that had experienced the greatest loss to follow-up.

The analytic sample for this study consisted of participants in six cities who reported being current smokers at each wave $(n=1644$ at wave $3, n=1572$ at wave 4 and $n=1505$ at wave 5), including those who were not followed up $(n=603$ from waves 3-4 and $n=393$ from waves 4-5) and those who were added to replenish the sample $(n=857)$. Cases with missing values in any of the study variables were excluded from the analyses, so the person-wave observations were 4601 in total.
The ethics review board at the Mexican National Institute of Public Health approved the ITC Mexico Survey protocol, and all participants provided written informed consent before they were interviewed.

\section{Measures}

Prices per cigarette at last purchase were calculated using responses to the questions, The last time you bought cigarettes for yourself, did you buy them by the carton, the pack or as single cigarettes, and How much did you pay for that (pack/ single cigarette/carton)? To adjust for different pack sizes, responses to the question When you bought the new pack, how many cigarettes did it contain? were used; if this information was missing or if values below 14 or above 25 were reported, ${ }^{17}$ it was assumed that packs contained 20 sticks of cigarettes (ie, the most common pack size). Price data from smokers who reported buying cartons were excluded since only few observations were available $(n=37)$. Prices were adjusted for inflation using the general price index from the Bank of Mexico; all price figures are reported in Mexican pesos (MX\$) of April 2012. The exchange rate in April 2012 was MX\$12.99 per US dollar (US\$).

Participants reported the cigarette brands last purchased. We confirmed that data from 2008 (wave 3) were consistent with previously reported 2006 (wave 1) and 2007 (wave 2) data, ${ }^{7}$ showing that the average price of each of the most popular international brands (Marlboro, Camel, Benson) was higher than the average price of each of the most popular national brands (Montana, Delicados, Boots, Raleigh); therefore, the binary classification of international versus national was used as an equivalent of the premium versus discount classification of brands. Less than $3 \%$ ( $n=8$ in 2008, $n=12$ in 2010 and $n=33$ in 2011) of the smokers reported having bought contraband brands at their last purchase; these cases were excluded from the brand analysis. Contraband brands were defined as those that were not included in the official list of cigarette brands with a permit to be sold in Mexico in each survey year. ${ }^{18}$

Standard sociodemographic variables such as age, sex, highest level of education and monthly household income were used as control variables. The seven response options for education were recoded to four (primary school or less, secondary school, high school and graduate or more), as were the seven options for monthly household income (MX\$0 to MX\$3000, MX\$3001 to MX\$5000, more than MX\$5000 and don't know). The number of surveys to which participants had responded was also included as a control variable in order to adjust for any confounding effects due to prior survey participation.

\section{Analyses}

Sample characteristics across waves were compared using simple $\chi^{2}$ tests. Rescaled weights were used to calculate point estimates of average self-reported prices of cigarettes and the proportion of smokers who purchased national brands at last purchase; comparisons of these estimates over time were conducted taking 2010 data as reference and adjusting the $\mathrm{p}$ values with Bonferroni's method. ${ }^{19}$ Additionally, a population-averaged panel model using generalised estimating equations (GEE) was estimated (normal or Gaussian distribution, identity link function, exchangeable correlation structure), ${ }^{20-22}$ regressing self-reported prices per cigarette at last purchase on type of brand (national or international), format of purchase (pack of cigarettes or single cigarettes), survey wave (dummy coded with 2010 as the reference group) and interactions between time and brand type in order to test whether changes in cigarette prices across waves significantly differed for national brands compared with international brands. 
To assess predictors of smoking national/discount brands, a GEE model was also estimated (binomial distribution, logit link function, exchangeable correlation structure), regressing selfreported purchase of national brands at last purchase on sociodemographic covariates and survey wave variables. The distribution of the dependent variables of both GEE models was checked to verify the specifications were adequate.

The statistical software Stata V.11.2 was used for all the analyses.

\section{RESULTS}

\section{Sample characteristics}

Table 1 shows the characteristics of the sample in each survey wave. Similar demographic characteristics were observed across waves except for education and income level; participants of wave 4 (2010) and wave 5 (2011) were more likely to be less educated and to have a higher household income than participants of wave 3 (2008). Only one-third of the respondents smoked more than five cigarettes per day, and most of them reported buying packs (76\%-82\%) and international brands $(78 \%-82 \%)$ at their last purchase. The percentage of people who purchased singles at last purchase increased over time (17\%-23\%).

\section{Price changes over time}

The average price of cigarettes increased from MX\$1.60 (95\% CI 1.55 to 1.65$)$ per cigarette in 2008 to $\mathrm{MX} \$ 1.83(95 \% \mathrm{CI}$ 1.78 to 1.88 ) in 2010 and MX\$2.19 (95\% CI 2.14 to 2.25 ) in 2011. The average price for international brands increased each year, whether purchased as a pack $(\mathrm{MX} \$ 1.46$ per cigarette in

Table 1 Demographic characteristics and smoking behaviour of sample, ITC Mexico Survey 2008, 2010, 2011 (unweighted means and proportions)

\begin{tabular}{|c|c|c|c|c|c|c|}
\hline \multirow{4}{*}{ Characteristics } & \multicolumn{6}{|c|}{ All current smokers at each wave } \\
\hline & \multicolumn{2}{|c|}{ Wave 3 (2008) } & \multicolumn{2}{|c|}{ Wave 4 (2010) } & \multicolumn{2}{|c|}{ Wave 5 (2011) } \\
\hline & \multicolumn{2}{|l|}{$n=1644$} & \multicolumn{2}{|l|}{$n=1572$} & \multicolumn{2}{|l|}{$n=1507$} \\
\hline & $\% /$ mean & $\mathrm{n}$ & $\% /$ mean & n & $\% /$ mean & n \\
\hline \multicolumn{7}{|l|}{ Age (years) } \\
\hline $18-24$ & 18.55 & 305 & 16.67 & 262 & 15.76 & 237 \\
\hline $25-39$ & 36.62 & 602 & 36.45 & 573 & 37.57 & 565 \\
\hline $40-54$ & 28.41 & 467 & 28.56 & 449 & 29.19 & 439 \\
\hline 55 or more & 16.42 & 270 & 18.32 & 288 & 17.49 & 263 \\
\hline \multicolumn{7}{|l|}{ Sex } \\
\hline Male & 63.14 & 1038 & 62.79 & 987 & 62.66 & 943 \\
\hline Female & 36.86 & 606 & 37.21 & 585 & 37.34 & 562 \\
\hline \multicolumn{7}{|l|}{ Education level* } \\
\hline Primary or less & 26.93 & 440 & 30.79 & 484 & 28.66 & 431 \\
\hline Secondary & 29.38 & 480 & 30.79 & 484 & 32.05 & 482 \\
\hline High school & 26.99 & 441 & 24.36 & 383 & 24.73 & 372 \\
\hline Graduate or more & 16.71 & 273 & 14.06 & 221 & 14.56 & 219 \\
\hline \multicolumn{7}{|l|}{ Monthly household income** } \\
\hline Low (MX\$0 to MX\$3000) & 25.03 & 409 & 28.18 & 443 & 21.51 & 324 \\
\hline Medium (MX\$3001 to MX\$5000) & 24.54 & 401 & 24.62 & 387 & 34.00 & 512 \\
\hline High (MX\$5001 or more) & 38.49 & 629 & 39.95 & 628 & 37.92 & 571 \\
\hline Don't know & 11.93 & 195 & 7.25 & 114 & 6.57 & 99 \\
\hline Waves of participation* & 2.89 & 1644 & 2.95 & 1567 & 2.76 & 1503 \\
\hline \multicolumn{7}{|l|}{ Smoking status } \\
\hline Less than daily & 33.9 & 557 & 33.04 & 517 & 32.02 & 481 \\
\hline Daily, five cigarettes per day or less & 30.55 & 502 & 30.29 & 474 & 32.29 & 485 \\
\hline Daily, more than five cigarettes per day & 35.54 & 584 & 36.68 & 574 & 35.69 & 536 \\
\hline \multicolumn{7}{|l|}{ Form of last cigarette purchase ${ }^{\star *}$} \\
\hline Pack of cigarettes & 82.31 & 1349 & 79.05 & 1234 & 76.14 & 1139 \\
\hline Single cigarette & 16.78 & 275 & 20.24 & 316 & 23.13 & 346 \\
\hline Carton of cigarette packs & 0.92 & 15 & 0.70 & 11 & 0.74 & 11 \\
\hline \multicolumn{7}{|l|}{ Brand of last cigarette purchase* $\dagger$} \\
\hline International & 78.42 & 1272 & 79.20 & 1226 & 82.02 & 1200 \\
\hline National & 21.58 & 350 & 20.80 & 322 & 17.98 & 263 \\
\hline \multicolumn{7}{|l|}{ Price per cigarette at last purchase $e^{* *} \ddagger$} \\
\hline International brands, packs of cigarettes & 1.47 & 1025 & 1.61 & 933 & 1.93 & 896 \\
\hline International brands, single cigarettes & 2.50 & 233 & 3.15 & 278 & 3.39 & 289 \\
\hline National brands, packs of cigarettes & 1.16 & 311 & 1.21 & 287 & 1.60 & 204 \\
\hline National brands, single cigarettes & 2.27 & 36 & 2.29 & 31 & 3.27 & 47 \\
\hline
\end{tabular}


Figure 1 Self-reported price per cigarette at last purchase, ITC Mexico Survey 2008, 2010 and 2011 (Mexican pesos of April 2012).

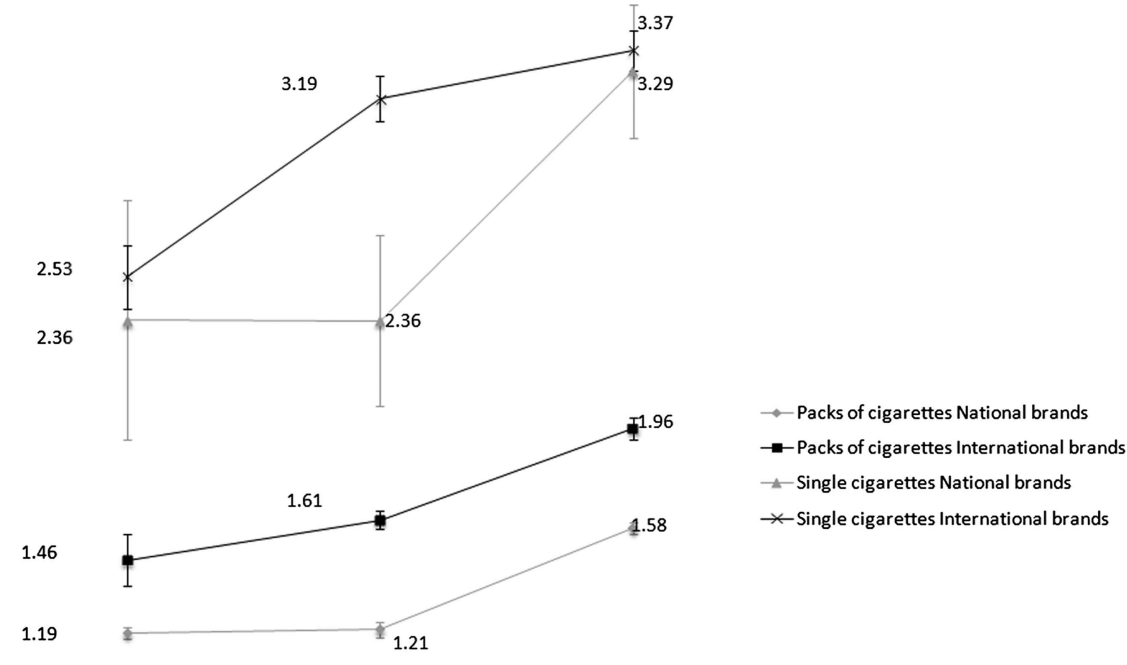

2008
2008, MX\$1.61 in 2010 and $\mathrm{MX} \$ 1.96$ in 2011; p $<0.01$ ) or as singles $(\mathrm{MX} \$ 2.53, \mathrm{MX} \$ 3.19$ and $\mathrm{MX} \$ 3.37$ per cigarette at each wave; $\mathrm{p}<0.01$ ) (figure 1). The increase in price for national brands was statistically significant only from 2010 to 2011 ( $p<0.01$ for both packs and singles).

Unlike prices of cigarettes sold in packs, prices of single cigarettes of international and national brands were similar in 2008 and in 2011 (MX\$2.53 and MX\$2.36 in 2008, MX\$3.37 and MX\$3.29 in 2011, respectively; p>0.01) (figure 1), that is, no price differentials across brands were observed in those years for singles.

The results from the GEE price model are consistent with the results described above (table 2): (1) price was lower in 2008 than in $2010(\mathrm{~B}=-0.26, \mathrm{p}<0.01)$ and higher in 2011 than in $2010(\mathrm{~B}=0.31, \mathrm{p}<0.01))$; (2) prices for national brands were lower than prices for international brands $(\mathrm{B}=-0.48, \mathrm{p}<0.01)$; (3) prices of national brands in 2010 were similar to prices of national brands in 2008 (ie, the coefficient for the interaction between national and 2008 was 0.24 , which almost completely offsets the main effect for the overall price difference between 2008 and 2010, $\mathrm{B}=-0.26$, as described above); (4) prices of

Table 2 Weighted GEE model for self-reported price per cigarette at last purchase

\begin{tabular}{|c|c|c|}
\hline Explanatory variables & Coefficient (B) & $95 \% \mathrm{Cl}$ \\
\hline \multicolumn{3}{|l|}{ Survey wave } \\
\hline $2008^{* *}$ & -0.26 & $(-0.30$ to -0.22$)$ \\
\hline $2011^{* *}$ & 0.31 & (0.27 to 0.34$)$ \\
\hline \multicolumn{3}{|c|}{ Brand of last cigarette purchase } \\
\hline National** & -0.48 & $(-0.53$ to -0.43$)$ \\
\hline \multicolumn{3}{|l|}{ Interactions } \\
\hline 2008_National ** & 0.24 & (1.15 to 1.37 ) \\
\hline 2011_National * * & 0.16 & (0.09 to 0.24$)$ \\
\hline \multicolumn{3}{|c|}{ Form of last cigarette purchase } \\
\hline Pack of cigarettes & -1.35 & $(-1.40$ to -1.30$)$ \\
\hline Observations & 4563 & \\
\hline
\end{tabular}

national brands increased from 2010 to 2011 (the coefficient of the interaction national and 2011 was $0.16 ; \mathrm{p}<0.01$ ); and (5) prices per unit of cigarettes sold in packs were lower than prices of single cigarettes $(\mathrm{B}=-1.35 ; \mathrm{p}<0.01)$.

\section{Predictors of preference for national/discount brands}

The percentage of smokers who purchased national brands appeared stable between 2008 (wave 3, 21.7\%) and 2010 (wave $4,22.2 \%$ ) but dropped in 2011 (wave 5, 19.2\%; p<0.05), which likely reflects the impact of the significant specific tax increase that raised the price of national brands relative to the price of international brands in that year.

Among those followed up, the percentage of smokers who switched from international brands to national brands was similar to the percentage of smokers who switched from national brands to international brands $(6.2 \%$ and $7.7 \%$ from 2008 to 2010 , respectively, and $4.4 \%$ and $6.3 \%$ from 2010 to 2011, respectively; $\mathrm{p}>0.01$ ).

When estimating models to determine factors related to smoking national brands as opposed to international brands, statistically significant correlates included being male and being relatively older, having lower education and lower income, and smoking more heavily (table 3 ).

\section{DISCUSSION}

The study provides further evidence of the effectiveness of excise taxes to increase cigarette prices. After cigarette excise taxes were increased in Mexico, prices went up by $14.0 \%$ between 2008 and 2010 and by $20.1 \%$ in 2011. However, prices did not increase in equal proportions for all brands. In 2008 , the relative price of national brands compared with international brands was 0.81 (MX\$1.19/MX\$1.46) if purchased as a pack or $0.94(\mathrm{MX} \$ 2.36 / \mathrm{MX} \$ 2.53)$ if purchased as singles, but decreased to approximately 0.75 (MX\$1.21/MX\$1.61 for packs, MX\$2.36/MX\$3.19 for singles) in 2010. Therefore, in response to the low tax increases of 2009 and 2010, the tobacco industry kept prices of cheaper national brands low, while setting higher prices for consumers of relatively higherpriced international brands. It was not until 2011 when the specific tax was significantly increased that the price of national brands was increased by a higher proportion than the price of 
Table 3 Predictors of purchasing national brands, weighted GEE model (dependent variable $=1$ if brand of last purchase was national)

\begin{tabular}{|c|c|c|}
\hline Explanatory variables & OR & $95 \% \mathrm{Cl}$ \\
\hline \multicolumn{3}{|l|}{ Age (years } \\
\hline 18 to 24 & 1 & \\
\hline 25 to 39 & 1.51 & 0.98 to 2.32 \\
\hline 40 to $54^{* *}$ & 2.59 & 1.69 to 3.98 \\
\hline 55 or more ${ }^{\star *}$ & 4.27 & 2.72 to 6.72 \\
\hline \multicolumn{3}{|l|}{ Sex } \\
\hline Male & 1 & \\
\hline Female** & 0.59 & 0.45 to 0.76 \\
\hline \multicolumn{3}{|l|}{ Education } \\
\hline Primary graduate or less & 1 & \\
\hline Secondary** & 0.50 & 0.37 to 0.67 \\
\hline High school graduate** & 0.32 & 0.22 to 0.45 \\
\hline College or more** & 0.23 & 0.15 to 0.34 \\
\hline \multicolumn{3}{|l|}{ Income } \\
\hline Low (MX\$0 to MX\$3000) & 1 & \\
\hline Medium (MX\$3001 to MX\$5000) & 0.88 & 0.72 to 1.07 \\
\hline High (MX\$5001 or more) ${ }^{*}$ & 0.79 & 0.63 to 0.99 \\
\hline Don't know & 0.92 & 0.68 to 1.23 \\
\hline \multicolumn{3}{|l|}{ Smoking status } \\
\hline Less than daily & 1 & \\
\hline Daily, five cigarettes per day or less & 1.22 & 0.98 to 1.53 \\
\hline Daily, more than five cigarettes per day ${ }^{* *}$ & 1.68 & 1.34 to 2.11 \\
\hline Waves of participation** & 1.26 & 1.15 to 1.37 \\
\hline \multicolumn{3}{|l|}{ Survey wave } \\
\hline 2008 & 1.11 & 0.95 to 1.30 \\
\hline 2010 & 1 & \\
\hline 2011 & 0.93 & 0.80 to 1.08 \\
\hline Observations & 4601 & \\
\hline
\end{tabular}

${ }^{*} p<0.05,{ }^{* *} p<0.01$.

GEE, generalised estimating equations.

international brands (between $31.3 \%$ and $39.6 \%$ vs $21.2 \%$ to $5.7 \%$, depending on the form of purchase), which resulted in a relative price of national brands above the 2008 value $(0.81=\mathrm{MX} \$ 1.58 / \mathrm{MX} \$ 1.96$ for packs, $0.98=\mathrm{MX} \$ 3.29 / \mathrm{MX}$ $\$ 3.37$ for singles).

Despite the reduction in the relative price of national brands in 2010, the percentage of smokers who purchased national brands remained stable in that year. This result is consistent with a previous study for Mexico that found no evidence of switching from international brands to national brands after the 2007 tax increase that was also passed onto consumers of international brands to a greater extent. ${ }^{7}$ The increase in the relative price of national brands in 2011, however, led to trading up to international brands, showing that continuing Mexican cigarette smokers seem to have a preference for international brands. Marlboro dominates the Mexican cigarette market with a market share of nearly $50 \%$.

Little is known about pricing of single cigarettes in Mexico. According to the findings of this study, retailers seem to have followed the pricing strategy of the industry as the prices of single cigarettes and packs exhibited a similar pattern. However, while recent taxes were effective in increasing the price of both, single cigarettes may become more widely available, thereby undermining tobacco control by facilitating youth access and cueing smoking behaviour among adults, including those who are trying to quit. ${ }^{23} 24$ The sale of single cigarettes is prohibited in Mexico since 1999, which is in line with article 16 of the FCTC ${ }^{14}$ but compliance and enforcement is poor. For example, in a sample of stores in Mexico City, 58\% sold single cigarettes. $^{25}$ More recent studies carried out in points of sale around schools indicate that sales of single cigarettes are widespread. $^{26} 27$ Data from this study indicate that between $18 \%$ and $22 \%$ of the smokers purchase single cigarettes $(18.2 \%$ in 2008 (wave 3), 20.0\% in 2010 (wave 4) and 21.9\% in 2011 (wave 5)). If the increase in purchase of singles has been accompanied by greater availability of singles, then tobacco taxes should be accompanied by comprehensive enforcement of other tobacco control policies.

As expected, our results indicate that heavier smokers with lower socioeconomic level are more likely to smoke cheaper national brands. Other studies have found similar results. For example, a study for Canada showed that discount brands and native brands were more popular among youth smokers with relatively less spending money and higher cigarette consumption. ${ }^{28}$ Another study found that the use of discount cigarettes among adults from the USA was associated with lower household income and higher daily consumption. ${ }^{6}$ In our study, lower education appears more strongly associated with smoking national brands than lower income. Hence, smoking international brands appears to reflect social distinctions and prestige that are above and beyond affordability concerns. These results are important for guiding tobacco control policy oriented towards specific population groups.

Besides national brands, contraband cigarettes constitute an option of cheaper cigarettes for Mexican smokers. According to data used in this study, a low percentage of smokers reported purchasing contraband brands (less than 3\%). It was not possible, however, to identify purchases of contraband cigarettes of brands that are legally sold in Mexico (eg, Marlboro or Camel) or other forms of contraband cigarettes such as counterfeit cigarettes. Additional research is required to better understand illicit trade penetration and the characteristics of the smokers who use these types of products.

The study has some limitations. Differences in the sample level of education and income were found across waves. However, the difference for education was not particularly strong, with the biggest difference being between wave 3 (2008) and wave 4 (2010) regarding lower education (26.9\% vs $30.8 \%)$. On the other hand, the difference for income may reflect increases in income levels over time, mostly moving people from the lowest to the middle category. Decreases in 'don't know' responses for income (from $11.9 \%$ in wave 3 (2008) to $7.2 \%$ in wave 4 (2010) and $6.6 \%$ in wave 5 (2011)) may be due to rapport between interviewer and participant, and trust building over time.

\section{CONCLUSIONS}

Tobacco taxes in Mexico were generally accompanied by price increases; however, the relatively low tax increases in 2009 and 2010 appear to have been passed onto consumers who smoked premium/international brands and not to those who smoked national/discount brands, as had been found for a prior assessment of price changes in response to higher ad valorem taxes implemented in 2007. ${ }^{7}$ The 2011 specific tax increase appears to have helped disrupt this market segmentation process, resulting in greater price increases for national brands. Evidence for trading up, from national brands to international brands, was found after the large increase in the specific tax in 2011 that narrowed the price gaps.

These results provide further evidence for the importance of tax policy as a tobacco control strategy, including strategies that 
produce price structures that do not encourage smokers to offset tax increases by switching to cheaper brands. In particular, these results illustrate the importance of using specific taxes rather than ad valorem taxes.

It is necessary, however, to adjust the specific tax for inflation in future to avoid decreases in the tax relative to cigarette price. $^{3}$ Also, considering cigarette taxes in the context of other tobacco control policies should help governments better tackle the tobacco epidemic.

\section{What this paper adds}

- The results of this study provide further evidence of tobacco industry pricing strategies in response to tax increases and changes in tax structure, as well as smokers' responses to resulting price changes.

- The relatively low tax increases implemented in 2009 and 2010 in Mexico resulted in price increases for premium/ international brands. The 2011 tax increase, however, which was a specific tax increase instead of ad valorem as had been the case till 2009 and was much higher than the specific tax increase of 2010, resulted in greater increases in prices of national brands versus international brands. This illustrates the relevance of using specific taxes instead of ad valorem taxes.

Contributors BSdeMJ contributed to the conception and design by proposing research questions and methods to address those questions. She also conducted the data analysis and participated in the drafting. She is responsible for the overall content as guarantor. JFT contributed to the conception and design of the article by proposing research questions and methods. He also participated in the analyses and interpretation of the data, as well as in the drafting. LMRS, MHÁ and FJC participated in the analysis and interpretation of the data. They also revised the article critically. All authors provided approval of the version submitted to Tobacco Control. No one else contributed substantially to the conception, design, analysis, interpretation, drafting and revision of the article.

Funding Funding for data collection came from the Mexican Consejo Nacional de Ciencia y Tecnología (Salud-2007-C01-70032), with additional funding for analysis provided by the National Cancer Institute at the National Institutes of Health (P01 CA138389)

Competing interests None.

Patient consent Obtained.

Ethics approval Ethics Review Board at the Mexican National Institute of Public Health.

Provenance and peer review Not commissioned; externally peer reviewed.

\section{REFERENCES}

1 Jha P, Chaloupka F. Curbing the epidemic. Governments and the Economics of Tobacco Control. Washington DC: The World Bank, 1999.

2 Chaloupka FJ, Hu T, Warner KE, et al. The taxation of tobacco products. In: Jha P, Chaloupka FJ, eds. Tobacco Control in Developing Countries. Washington DC: The World Bank, 2000:237-72.

3 IARC. Handbooks of Cancer Prevention in Tobacco Control, Volume 14 Effectiveness of tax and price policies in tobacco control. Lyon: International Agency for Research on Cancer, 2011.

4 U.S. Department of Health and Human Services. Preventing Tobacco Use Among Youth and Young Adults: A Report of the Surgeon General. Atlanta, GA: U.S. Department of Health and Human Services, Centers for Disease Control and Prevention, National Center for Chronic Disease Prevention and Health Promotion, Office on Smoking and Health, 2012.
5 Tsai Y, Chung-Lin Y, Chin-Shyan C, et al. The effect of Taiwan's tax-induced increases in cigarette prices on brand-switching and the consumption of cigarettes. Health Econ 2005:14:627-41.

6 Cummings KM, Hyland $A$, Lewit $E$, et al. Use of discount cigarettes by smokers in 20 communities in the United States, 1988-1993. Tob Control 1997;6:S25-30.

7 Saenz de Miera B, Thrasher JF, Chaloupka FJ, et al. Self-reported price of cigarettes, consumption and compensatory behaviours in a cohort of Mexican smokers before and after a cigarette tax increase. Tob Control 2010;19:481-7.

8 Evans WN, Farrelly MC. The compensating behavior of smokers: taxes, tar, and nicotine. Rand J Econ 1998:29:578-95.

9 Gilmore AB, Tavakoly B, Taylor $G$, et al. Understanding tobacco industry pricing strategy and whether it undermines tobacco tax policy: the example of the UK cigarette market. Addiction 2013;108:1317-26.

10 World Health Organization. WHO Technical Manual on Tobacco Tax Administration. Geneva, Switzerland: World Health Organization, Tobacco Free Initiative, 2010.

11 The relatively low specific tax implemented in 2010 had been legislated to be followed by specific taxes of MX\$0.06 per cigarette in 2011, MX $\$ 0.08$ per cigarette in $2012, M X \$ 0.10$ per cigarette in 2013 , but by the end of 2010 the law was changed so the much higher specific tax substituted the small, gradual increases that had been approved the year before.

12 Waters H, Saenz de Miera B, Ross H, et al. The economics of tobacco and tobacco taxation in Mexico. Paris, France: International Union Against Tuberculosis and Lung Disease, 2010.

13 Jimenez-Ruiz JA, Saenz de Miera B, Reynales-Shigematsu LM, et al. The impact of taxation on tobacco consumption in Mexico. Tob Control 2008;17:105-10.

14 World Health Organization. Framework Convention on Tobacco Control. Geneva, Switzerland: World Health Organization, Tobacco Free Initiative, 2003.

15 Fong GT, Cummings KM, Borland R, et al. The conceptual framework of the International Tobacco Control Policy Evaluation Project. Tob Control 2006;15(Supp 3):iii3-11.

16 Thrasher JF, Boado M, Sebrie EM, et al. Smoke-free policies and the social acceptability of smoking in Uruguay and Mexico: Findings from the international tobacco control policy evaluation project. Nicotine Tob Res 2009;11:591-99.

17 Packs of cigarettes sold in Mexico are of different sizes, but the General Law for Tobacco Control (article 16), in force from May 2008, establishes limits, 14 cigarettes per pack minimum and 25 maximum. According to the ITC Mexico Survey, between $0.5 \%$ and $2 \%$ of participants whose last purchase was a pack reported a pack size of less than 14 cigarettes or more than 25 (28 out of 1349 at wave 3, 6 out of 1234 at wave 4 and 7 out of 1139 at wave 5). However, the reported prices of those packs were within the price interval for packs with regular pack sizes; therefore, it seems pack sizes were reported with error in former cases. Since approximately $90 \%$ of participants whose last purchase was a pack reported pack sizes of 20 cigarettes (1228 out of 1349 at wave 3, 1080 out of 1234 at wave 4 and 1033 out of 1139 at wave 5), we used this value to replace pack sizes out of the legal limits.

18 Ministry of Finance and Public Credit. Annex 11 of the Miscellaneous Fiscal Resolution. Official Gazette of the Federation, 2008, 2010, 2011.

19 Seber GAF. Linear Regression Analysis. Nueva York: John Wiley and Sons, 1977.

20 Liang K, Zeger SL. Regression analysis for correlated data. Annu Rev Public Health 1993:14:43-68

21 Zeger SL, Liang KY. Longitudinal data analysis for discrete and continuous outcomes. Biometrics 1986;42:121-30.

22 Hanley JA, Negassa A, Edwardes MD, et al. Statistical analysis of correlated data using generalized estimating equations: an orientation. Am J Epidemiol 2003; 157:364-75.

23 Thrasher JF, Villalobos V, Dorantes-Alonso A, et al. Does the availability of single cigarettes promote or inhibit cigarette consumption? Perceptions, prevalence and correlates of single cigarette use among adult Mexican smokers. Tob Control 2009:18:431-37

24 Thrasher JF, Villalobos V, Barnoya J, et al. Consumption of single cigarettes and quitting behavior: A longitudinal analysis of Mexican smokers. BMC Public Health 2011;11:134. Published online: 25 February 2011.

25 Kuri Morales PA, Cortes Ramirez M, Cravioto Quintana P. Prevalence and risk factors related to sale of cigarettes to minors in stores in Mexico City. Salud Pub Mex 2005:47:402-12.

26 Hernández-Ávila JE, Tirado-Ramírez E, Santos-Luna R, et al. Use of Geographical Information Systems for billboards and points-of-sale surveillance in two Mexico cities. Salud Pub Mex 2007;49(suppl 2):241-46.

27 Rodríguez-Bolaños R, Reynales-Shigematsu LM, Ibáñez-Hernández NA, et al. Monitoring strategy for control of tobacco in Mexico: advertising, promotion and sponsorship, packaging and labeling. Salud Pub Mex 2010;52(suppl 2):S254-66

28 Leatherdale ST, Ahmed R, Barisic A, et al. Cigarette brand preference as a function of price among smoking youths in Canada: are they smoking premium, discount or native brands? Tob Control 2009:18:466-73. 